\title{
Podocalyxin-Like Protein 1 Expression and Correlation with Clinical Characteristics in Epithelial Serous and Mucinous Ovarian Carcinoma and Tumor-Like Lesions
}

\author{
Feng Ye ${ }^{a}$ Ying Hu${ }^{a} \quad$ Caiyun Zhou ${ }^{b}$ Yuting Hu${ }^{a}$ Huaizeng Chen ${ }^{a}$ \\ aWomen's Reproductive Health Key Laboratory of Zhejiang Province, and bepartment of Pathology, \\ Women's Hospital, Zhejiang University School of Medicine, Hangzhou, PR China
}

\section{Key Words}

Clinical characteristics • Epithelial ovarian carcinoma •

PCLP1 · Podocalyxin-like protein 1

\begin{abstract}
Objective: Podocalyxin-like protein 1 (PCLP1) may be involved in the invasion and metastasis of tumors. However, to date the role of PCLP1 in the progression of epithelial ovarian carcinoma has not been investigated. Methods: PCLP1 expression was examined by immunohistochemistry in 471 cases with various degrees of ovarian epithelial lesions, including 46 cases of normal ovarian epithelial tissue, 105 benign serous tumors, 74 borderline serous tumors, 94 serous carcinomas, 58 benign mucinous tumors, 50 borderline mucinous tumors and 44 mucinous carcinomas. Associations between PCLP1 expression and various clinical characteristics were analyzed. Results: PCLP1 expression in mucinous carcinoma and borderline mucinous tumor tissues was found to be significantly lower than that observed in normal and benign mucinous tumor tissue. In addition, PCLP1 expression was significantly lower in mucinous carcinoma patients in advanced clinical stage and with poor differentiation of tumor cells. No positive results were observed in serous carcinomas. Conclusions: Our findings suggest that
\end{abstract}

PCLP1 may be involved in the progression of ovarian mucinous lesions but not in serous lesions. Low PCLP1 expression may be a potential predictor of a poor prognosis in mucinous carcinomas.

Copyright $\odot 2012$ S. Karger AG, Basel

\section{Introduction}

Podocalyxin-like protein 1 (PCLP1), a type I transmembrane glycoprotein, is a member of the CD34 subfamily of sialomucins [1]. It has some structural and functional similarity with the L-selectin ligand CD34 [2] and endoglycan [3]. PCLP1 consists of an extracellular mucin-like domain with numerous sites for $\mathrm{N}$ - and $\mathrm{O}$-linked glycosylation, a transmembrane domain and an intracellular domain possessing several potential phosphorylated sites. On the one hand, PCLP1 is described as an antiadhesion molecule on the kidney podocyte, which maintains the integrity of the glomerular filtration slits by charge repulsion [4]. PCLP1 is also expressed in other cell types, including high endothelial venules [1] and early hematopoietic progenitors, precursors of hematopoietic stem cells [5]. On the other hand, PCLP1 expressing high endothelial venules acts as an adhesion molecule mediat- 
ing L-selectin-dependent lymphocyte recruitment [2]. Subsequent studies have revealed that PCLP1 is also highly expressed in undifferentiated human embryonic stem cells [6] and is gradually lost during differentiation. Hence, PCLP1 seems to have quite different functions depending on the cell type.

It is well known that regulation of cell-cell adhesion is the molecular basis of a series of important physiological and pathological processes in normal tissue, playing a major role in tumor invasion and metastasis. It has been proposed that impaired cell-cell adhesion, which results in disruption of epithelial cell junctions, is thought to facilitate the emergence of carcinoma progression. Abnormal expression of key molecules involved in the regulation of cell-cell adhesion will affect tumor invasion and metastasis. Hence, the potential anti- and pro-adhesive properties of PCLP1 suggest that it may be involved in tumor invasion and metastasis, which attracts a great deal of attention. Recent studies have shown that PCLP1 is expressed in hepatic and [7] prostate carcinomas [8], the majority of acute leukemias [9], thyroid carcinomas [10], invasive breast cancers [11], malignant astrocytic tumors [12], human embryonal carcinomas [13] and Wilms tumors [14]. Overexpression of PCLP1 on malignant cells results in metastatic spread due to its anti- and pro-adhesive properties.

Ovarian carcinoma is the deadliest of the gynecological malignancies because of its extremely rapid, extensive spread in the early stages. The biological characteristics of its extraovarian invasion and lymph node metastases, which are still poorly understood, are the major causes of clinical treatment failure for patients with ovarian carcinoma. The prognosis of patients with ovarian carcinoma is still not optimistic. Previous studies have demonstrated that many molecules involved in cell-cell adhesion are associated with the invasion and metastasis of ovarian carcinomas $[15,16]$. Owing to the potential property of PCLP1 to be an L-selectin ligand, the expression pattern and function of PCLP1 may be important in the progression of ovarian carcinomas.

Epithelial ovarian carcinoma is the most common subtype of ovarian cancer that accounts for approximately $90 \%$ of all ovarian cancer cases. Hence, in this immunohistochemistry study, we assessed PCLP1 expression in various ovarian epithelial lesions to determine whether PCLP1 was involved in the progression of epithelial ovarian carcinoma. Furthermore, we analyzed the association between PCLP1 expression and various clinical characteristics to determine whether PCLP1 was a predictor of epithelial ovarian carcinoma progression.

\section{Patients and Methods}

\section{Samples and Patients}

The specimens $(n=471)$ were randomly obtained from patients in the Pathological Department of the Women's Hospital, Zhejiang University School of Medicine (China), between March 1997 and May 2008. Tissue sampling was approved by the Medical Ethics Committee of the Affiliated Women's Hospital, Zhejaing University School of Medicine, and written informed consent was obtained from all participants involved in this study. The samples consisted of 46 normal ovarian epithelia, 105 benign serous tumors, 74 borderline serous tumors, 94 serous carcinomas (including 6, 26, 58 and 4 in FIGO stage I, II, III and IV, respectively), 58 benign mucinous tumors, 50 borderline mucinous tumors and 44 mucinous carcinomas (including 20, 6 and 18 in FIGO stage I, II and III, respectively). None of the patients had received chemotherapy, immunotherapy or radiotherapy before specimen collection. The complete parameters were collected, including clinical stage, tumor cell differentiation, CA125 expression and patient age.

Ethical approval from the Medical Ethics Committee at the Cancer Center of the Affiliated Women's Hospital for the collection or analysis of existing data was not required due to the retrospective design of the study, and, therefore, written consent given by the patients was not needed for their hospitalization and research. Furthermore, only anonymous data were retrieved from this database and the Ethics Committee waived the need for approval and consent.

\section{Immunohistochemistry}

All tissues were immediately fixed in 10\% neutralized formalin for $24 \mathrm{~h}$ prior to processing in paraffin wax according to standard procedures. Dewaxing and rehydration of the tissue sections was performed according to standard procedures. Hydrated autoclave pretreatment was performed by boiling the samples in 10 $\mathrm{mM}$ citrate buffer ( $\mathrm{pH}$ 6.0) for $2 \mathrm{~min}$. Endogenous peroxidase activity was blocked with $3 \%$ hydrogen peroxidase for $10 \mathrm{~min}$ at room temperature (RT). Slides were incubated with the primary monoclonal mouse antibody diluted 1:150 in Tris-buffered saline (50 mM Tris-HCl, $150 \mathrm{mM} \mathrm{NaCl}, \mathrm{pH}$ 7.4) at RT for $1 \mathrm{~h}$ followed by incubation with Dako EnVision ${ }^{\mathrm{TM}}$ peroxidase (Dako Diagnostica, Hamburg, Germany) for $30 \mathrm{~min}$ at RT. Finally, after adding 3,3'diaminobenzidine tetrahydrochloride (Dako) for visualization, the slides were counterstained with Mayer's hematoxylin, rinsed in tap water, dehydrated, placed in xylene and mounted at RT. Slides were washed three times for $3 \mathrm{~min}$ in PBS between each step. The mouse anti-human monoclonal antibody specific for PCLP1 was purchased from Santa Cruz (sc-23903; Santa Cruz, Calif., USA). Blank controls were obtained by replacing the primary antibody with normal mouse serum (Dingguo, Beijing, China).

Positive cells were indicated by the presence of brown staining in the cytoplasm and membrane. We counted the number of positively stained cells out of 100 in 10 random fields ( $\times 400$ objective) and represented this number as the percentage of positive cells. The semiquantitative immunoreactive score was evaluated from 0 to 6 based on the percentage of positive cells and stain intensity. Percentage of positive cells was scored as follows: $0,<5 \%$ positive cells; $1,5-25 \%$ positive cells; $2,26-75 \%$ positive cells, and $3,>76 \%$ positive cells. Stain intensity was scored as follows: 0, weaker than 
Table 1. PCLP1 expression in different ovarian epithelial lesions

\begin{tabular}{|c|c|c|c|c|c|c|c|c|c|c|c|c|}
\hline & \multirow{2}{*}{$\begin{array}{l}\text { Total } \\
(\mathrm{n}=319)\end{array}$} & \multicolumn{5}{|c|}{ Serous epithelial lesions } & \multirow{2}{*}{$\begin{array}{l}\text { Total } \\
(\mathrm{n}=198)\end{array}$} & \multicolumn{5}{|c|}{ Mucinous epithelial lesions } \\
\hline & & $\begin{array}{l}- \\
(\mathrm{n}=7)\end{array}$ & $\begin{array}{l}+ \\
(\mathrm{n}=6)\end{array}$ & $\begin{array}{l}++ \\
(\mathrm{n}=42)\end{array}$ & $\begin{array}{l}+++ \\
(\mathrm{n}=264)\end{array}$ & $\begin{array}{l}\mathrm{p} \\
\text { value }\end{array}$ & & $\begin{array}{l}- \\
(\mathrm{n}=20)\end{array}$ & $\begin{array}{l}+ \\
(\mathrm{n}=18)\end{array}$ & $\begin{array}{l}++ \\
(\mathrm{n}=34)\end{array}$ & $\begin{array}{l}+++ \\
(\mathrm{n}=126)\end{array}$ & $\begin{array}{l}\mathrm{p} \\
\text { value }\end{array}$ \\
\hline & & & & & & $0.520^{*}$ & & & & & & $0.0001^{* *}$ \\
\hline Normal & 46 & 2 & 1 & 7 & 36 & $0.195^{\mathrm{a}}$ & 46 & 2 & 1 & 7 & 36 & $0.825^{\mathrm{g}}$ \\
\hline Benign & 105 & 3 & 1 & 10 & 91 & $0.228^{\mathrm{b}}$ & 58 & 2 & 6 & 5 & 45 & $0.009^{h}$ \\
\hline Borderline & 74 & 1 & 3 & 11 & 59 & $\begin{array}{l}0.819^{\mathrm{c}} \\
0.514^{\mathrm{d}}\end{array}$ & 50 & 11 & 4 & 7 & 28 & $\begin{array}{l}0.009^{\mathrm{i}} \\
0.455^{\mathrm{j}}\end{array}$ \\
\hline Carcinoma & 94 & 1 & 1 & 14 & 78 & $\begin{array}{l}0.444^{\mathrm{e}} \\
0.518^{\mathrm{f}}\end{array}$ & 44 & 5 & 7 & 15 & 17 & $\begin{array}{l}0.0001^{\mathrm{k}} \\
0.0001^{1}\end{array}$ \\
\hline
\end{tabular}

${ }^{*} \chi^{2}=2.262,{ }^{* *} \chi^{2}=21.203$ ( $\mathrm{p}$ value of four groups). ${ }^{\mathrm{a}} \mathrm{Z}=-1.295$, normal vs. benign serous tumor; ${ }^{\mathrm{b}} \mathrm{Z}=-1.206$, benign serous tumor vs. borderline serous tumor; ${ }^{c} Z=-0.229$, normal vs. borderline serous tumor; ${ }^{d} Z=-0.611$, borderline serous tumor vs. serous carcinoma; ${ }^{\mathrm{e}} \mathrm{Z}=-0.765$, normal vs. serous carcinoma; ${ }^{\mathrm{f}} \mathrm{Z}=-0.647$, benign serous tumor vs. serous carcinoma; ${ }^{\mathrm{g}} \mathrm{Z}=-0.221$, normal vs. benign mucinous tumor; ${ }^{\mathrm{h}} \mathrm{Z}=-2.612$, benign mucinous tumor vs. borderline mucinous tumor; ${ }^{\mathrm{i}} \mathrm{Z}=-2.629$, normal vs. borderline mucinous tumor; ${ }^{j} \mathrm{Z}=-0.747$, borderline mucinous tumor vs. mucinous carcinoma; ${ }^{\mathrm{k}} \mathrm{Z}=-3.802$, normal vs. mucinous carcinoma; ${ }^{1} \mathrm{Z}=-3.668$, benign mucinous tumor vs. mucinous carcinoma.

buff; 1 , yellow; 2, brown, and 3, dark brown. The final score was a combination of the two scores as follows: $-(0),+(1-2),++(3-4)$ and $+++(5-6)$.

\section{Statistical Analysis}

The SPSS 10.0 software package was used to perform all the statistical analyses. Differences in PCLP1 expression among the different groups were evaluated by the Kruskal-Wallis $\mathrm{H}$ and the Mann-Whitney U tests. Associations between PCLP1 expression and clinical pathologic factors were analyzed by the Spearman and Kendall tests. Values of $\mathrm{p}<0.05$ were considered to be statistically significant.

\section{Results}

\section{Expression of PCLP1 in Various Degrees of Ovarian Epithelial Lesions}

Moderate or strong PCLP1 expression was predominantly observed on the cell membrane and cytoplasm of normal ovarian epithelial and benign mucinous tumor tissues. In contrast, weak or moderate PCLP1 expression was observed in borderline mucinous tumor and mucinous carcinoma tissues (fig. 1). There were significant differences in PCLP1 expression among normal ovarian epithelia, benign mucinous tumor, borderline mucinous tumor and mucinous carcinoma groups $(\mathrm{p}=0.000)$. PCLP1 expression was lower in mucinous carcinomas than in normal $(\mathrm{p}=0.000)$ or benign mucinous tumor tissues ( $\mathrm{p}=0.000$, table 1 ). In addition, PCLP1 expression was significantly lower in borderline mucinous tumor than in normal $(\mathrm{p}=0.009)$ and benign mucinous tumor tissues $(\mathrm{p}=0.009)$.

Our results also showed that moderate or strong PCLP1 expression was predominant on both the cell membrane and the cytoplasm in almost all ovarian serous epithelial lesions, including normal ovarian epithelial tissue, and benign serous tumor, borderline serous tumor and serous carcinoma tissues (fig. 2). The blank controls showed negative PCLP1 staining (data not shown). There was no significant difference in PCLP1 expression among all four groups of serous epithelial lesions (table 1).

\section{Associations between PCLP1 Expression and Clinical Characteristics}

Analysis of associations between PCLP1 expression and some important clinical pathological factors showed that PCLP1 expression was not correlated with clinical stages, CA125 expression levels or age in serous epithelial lesions (data not shown).

In contrast to the serous carcinoma patients, PCLP1 expression was significantly lower with advanced clinical stage $(\mathrm{p}=0.019)$ and poor differentiation of tumor cells $(\mathrm{p}=0.004)$ in 44 mucinous carcinoma patients (table 2). PCLP1 expression was not correlated with either CA125 expression levels or age in mucinous epithelial lesions. 

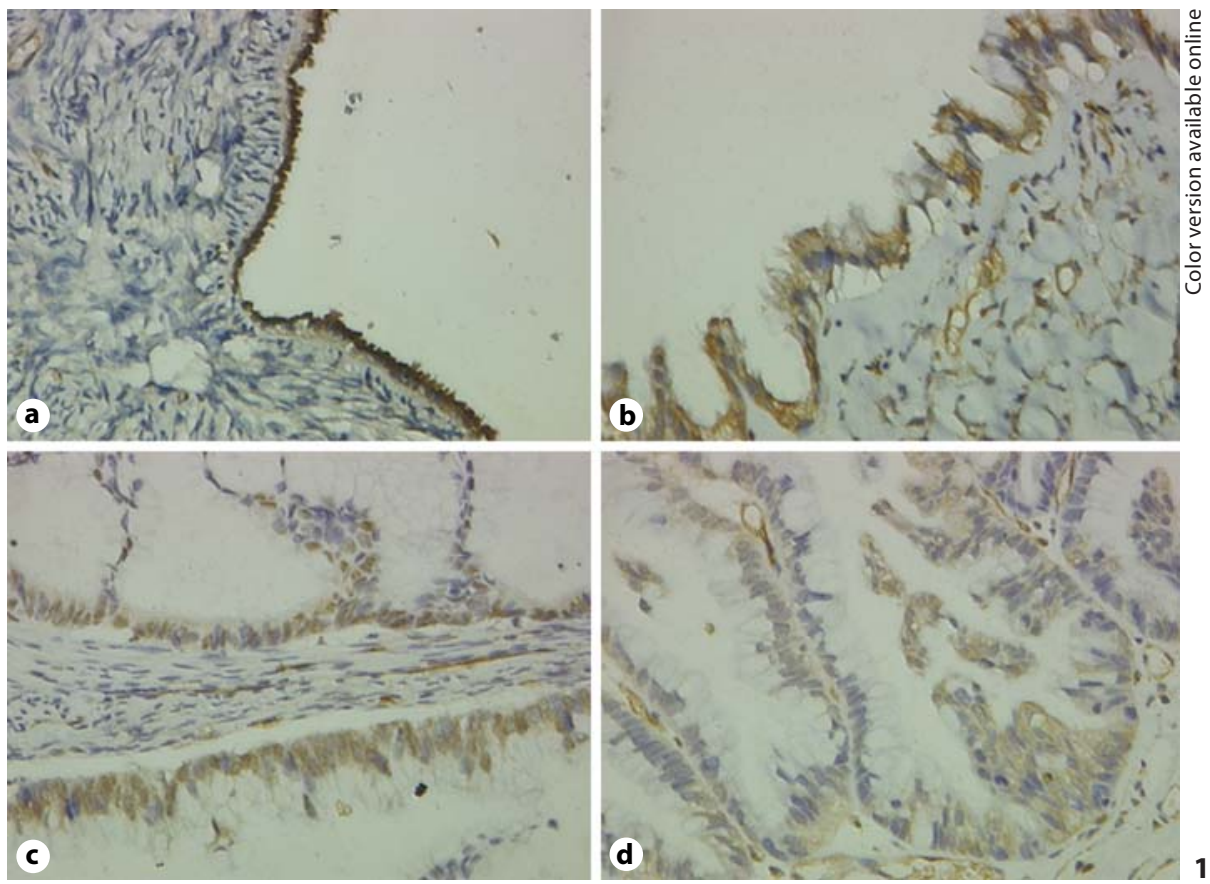

Fig. 1, 2. PCLP1 expression and localization in normal ovarian epithelia (a), benign (b) and borderline mucinous tumors (c), and mucinous (1d) and serous carcinomas (2d). The ovarian epithelial tissue shows both cell membrane and cytoplasm staining of positive cells with distinct brown coloration. Color refers to the online version only.
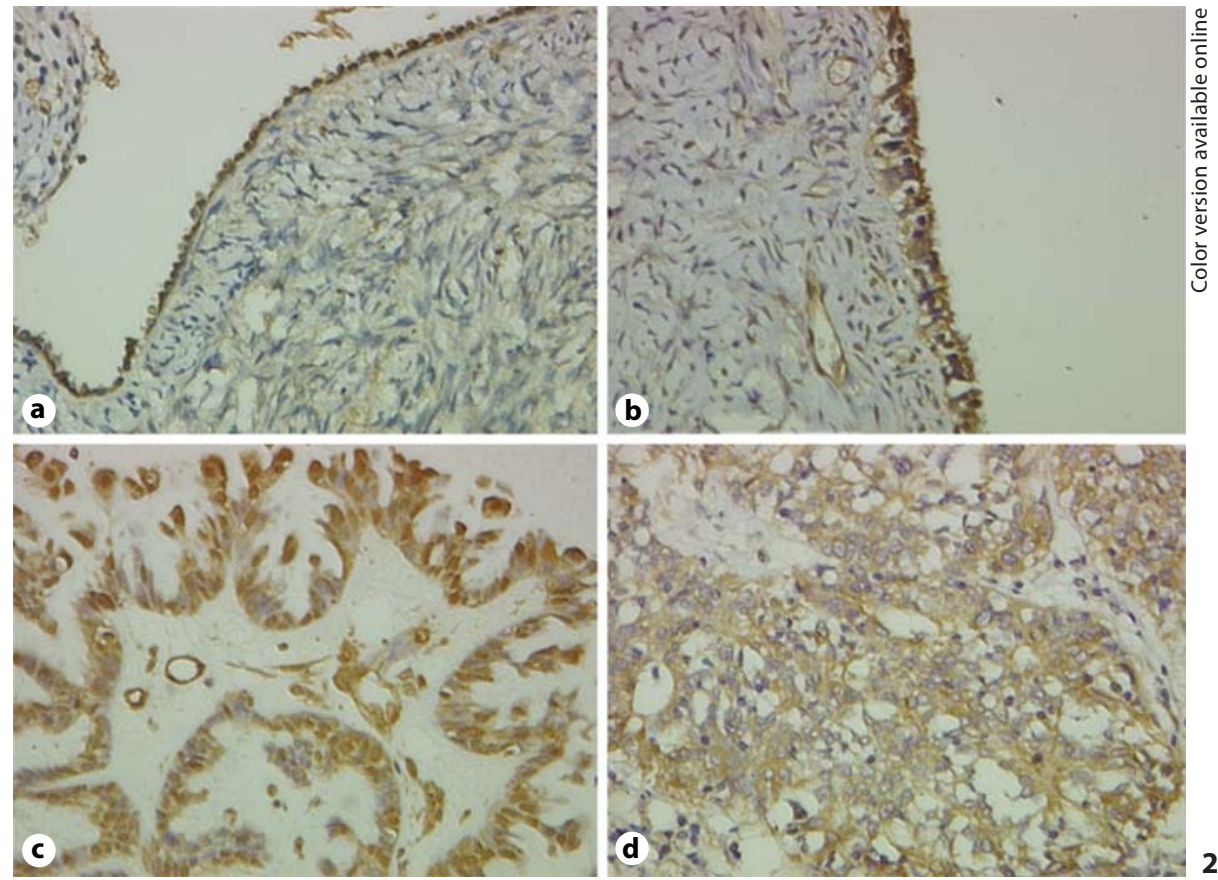

\section{Discussion}

The human PCLP1 gene is located at chromosome $7 \mathrm{q} 32-\mathrm{q} 33$, encoding for a protein of approximate 528 amino acids [17]. Structurally similar to CD34, PCLP1 consists of an extracellular mucin-like domain with nu- merous sites for $\mathrm{N}$ - and $\mathrm{O}$-linked glycosylation, a transmembrane domain and an intracellular domain possessing several potential phosphorylated sites. PCLP1 is normally expressed on kidney podocytes, vascular endothelia, hematopoietic progenitors and a subset of neurons [18]. 
Table 2. The association of PCLP1 expression with clinical stages and tumor cell differentiations

\begin{tabular}{|c|c|c|c|c|c|c|c|c|c|c|c|c|c|c|}
\hline & \multirow{2}{*}{$\begin{array}{l}\text { Total } \\
(\mathrm{n}=94)\end{array}$} & \multicolumn{6}{|c|}{ Serous carcinoma } & \multirow{2}{*}{$\begin{array}{l}\text { Total } \\
(\mathrm{n}=44)\end{array}$} & \multicolumn{6}{|c|}{ Mucinous carcinoma } \\
\hline & & $\begin{array}{l}- \\
(\mathrm{n}=1)\end{array}$ & $\begin{array}{l}+ \\
(\mathrm{n}=1)\end{array}$ & $\begin{array}{l}++ \\
(\mathrm{n}=14)\end{array}$ & $\begin{array}{l}+++ \\
(\mathrm{n}=78)\end{array}$ & $\begin{array}{l}\text { Correlation } \\
\text { coefficient }\end{array}$ & & & $\begin{array}{l}- \\
(\mathrm{n}=5)\end{array}$ & $\begin{array}{l}+ \\
(\mathrm{n}=7)\end{array}$ & $\begin{array}{l}++ \\
(\mathrm{n}=15)\end{array}$ & $\begin{array}{l}+++ \\
(\mathrm{n}=17)\end{array}$ & $\begin{array}{l}\text { Correlation } \\
\text { coefficient }\end{array}$ & \\
\hline Clinical stage & & & & & & 0.190 & 0.055 & & & & & & -0.318 & 0.019 \\
\hline I & 6 & 1 & 0 & 1 & 4 & & & 20 & 1 & 2 & 6 & 11 & & \\
\hline II & 26 & 0 & 1 & 6 & 19 & & & 6 & 1 & 1 & 1 & 3 & & \\
\hline III & 58 & 0 & 0 & 6 & 52 & & & 18 & 3 & 4 & 8 & 3 & & \\
\hline IV & 4 & 0 & 0 & 1 & 3 & & & & & & & & & \\
\hline Differentiation & & & & & & 0.115 & 0.247 & & & & & & -0.383 & 0.004 \\
\hline Well & 8 & 0 & 1 & 1 & 6 & & & 18 & 0 & 2 & 6 & 10 & & \\
\hline Moderate & 34 & 1 & 0 & 6 & 27 & & & 18 & 2 & 3 & 7 & 6 & & \\
\hline Poor & 52 & 0 & 0 & 7 & 45 & & & 8 & 3 & 2 & 2 & 1 & & \\
\hline
\end{tabular}

The role of PCLP1 in the cell-cell adhesion process has been examined in many studies, focusing on its effects on invasion and metastasis of malignant tumors. Aberrant PCLP1 overexpression has recently been detected in a range of cancers by several studies. However, the results of our study showed that PCLP1 was abundantly expressed in normal ovarian epithelial cells, and expression tended to decrease from normal to malignant tissues. In mucinous carcinoma and borderline tumor tissues, PCLP1 expression was significantly lower than in normal and benign mucinous tumors. An unexpected finding was that PCLP1 expression did not differ from normal to serous carcinomas. Since PCLP1 is involved in the regulation of cell-cell adhesion, our findings suggest that PCLP1 may play a role in the progression of ovarian mucinous but not serous lesions. Low PCLP1 expression in mucinous carcinomas compared to normal ovarian epithelial cells suggests that PCLP1 may have potential as a molecular marker for the detection of ovarian mucinous carcinomas.

PCLP1 overexpression in kidney epithelial cells modifies tight cell junctions and decreases junction-dependent transepithelial resistance because of its anti-adhesive properties [19]. Actually, most of the studies have found the same results when PCLP1 was overexpressed in carcinoma cells. Since the degree and mechanism of junction disruption varies widely with tumor subtype, clinical stage and tumor differentiation [11], it is reasonable to believe that a downregulation of PCLP1 might also play a role in junction disruption. Pro-adhesive or other unknown functions of PCLP1 may be reduced in ovarian mucinous cystadenocarcinoma progression. In addition, we found no significant difference in PCLP1 expression between borderline mucinous tumor and mucinous carcinoma tissues, suggesting there may be a turning point from benign mucinous cystadenoma to borderline lesions.

Ovarian cancer has become a fatal threat to women's lives and health, and its mortality ranks first among gynecological malignancies [20]. There are various subtypes of epithelial ovarian cancer of morphological heterogeneity. A recent study suggested that epithelial ovarian cancer is not merely a single disease but rather a collection of several diseases. The same molecule has different expression profiles as well as different values depending on the various histological types. This means that PCLP1 may not participate in the progression of serous carcinomas, which differ markedly from mucinous carcinomas.

Previous studies have demonstrated that PCLP1 has almost the opposite functions of adhesion depending on the cell type. To date, no consensus was reached about the detailed functions of PCLP1, especially in the field of carcinoma progression. Some researchers reported that overexpression of PCLP1 in malignant cells results in metastatic spread via both its anti- and pro-adhesive properties. In theory, the anti-adhesive role of PCLP1 could cause cell shedding from primary tumors and their entry into the circulatory system. Simultaneously, the pro-adhesive properties of PCLP1 could result in secondary tumor colony formation via its selectin ligand activity associated with selectin-expressing host cells [21]. Recent evidence indicates that PCLP1 is an E- and L-selectin ligand on LS174T colon carcinoma cells [22], which may explain the metastatic potential of PCLP1 overexpression on many types of carcinoma cells. However, this hypoth- 
esis has to be confirmed by further studies. Interestingly, aberrant PCLP1 expression is often associated with the most aggressive cancers and probably involved in metastasis. Especially the anti-adhesive properties of PCLP1 have been widely regarded as the dominant contribution of this molecule to metastatic progression [11]. Moreover, PCLP1 also acts as an important marker which can be recognized by a cytotoxic antibody to selectively bind and kill cancer cells [23]. PCLP1 overexpression is an independent predictor of breast cancer progression [11]. In our study, PCLP1 expression was relatively decreased in mucinous carcinomas, too. Probably PCLP1-induced junction disruption is more significant in mucinous carcinomas. The effect of low PCLP1 expression on carcinoma cells requires further investigation. Hence, an indepth investigation on the functions of PCLP1 may help to improve cancer treatment.

Some clinical characteristics that are usually examined to follow up the progression of carcinomas may be able to predict the prognosis of patients, which is very important in clinical treatment. In our study, we showed that PCLP1 expression is significantly decreased in mucinous carcinoma patients in advanced clinical stage with poor differentiation. Consequently, PCLP1 may be involved in the development and progression from normal ovarian tissue to mucinous carcinoma tissue. PCLP1 expression was decreased in higher clinical stages, which also confirms that the protein plays an important role in the regulation of tumor cell differentiation, which is in agreement with results in breast carcinomas and pancreatic ductal adenocarcinomas. PCLP1 was also reported as a marker of poorly differentiated tumors [24]. In our study in a medium-sized study cohort $(\mathrm{n}=44)$, low PCLP1 expression was very likely to be a prognostic predictor of mucinous carcinoma, but PCLP1 expression did not correlate with CA125 expression levels in these carcinomas. This may be explained by the fact that CA125 itself is not a specific indicator of mucinous carcinoma progression. Furthermore, PCLP1 expression was neither correlated with age in general nor with any clinical characteristic in serous ovarian lesions. Possibly PCLP1 does not participate in the progression of serous carcinomas.

In summary, our study showed that PCLP1 expression decreases from normal to malignant lesions suggesting that PCLP1 may play a role in the progression of ovarian mucinous but not serous lesions. The negative correlations of PCLP1 expression with clinical stage and tumor cell differentiation indicate that PCLP1 is a potential predictor of a poor prognosis in mucinous carcinoma.

\section{Acknowledgments}

This work was supported by a grant from the Zhejiang Natural Science Foundation of China (Y204049, Y207162 and Y2110200) and the National Nature Science foundation of China (No. 30973380).

\section{References}

${ }_{1}$ Kershaw DB, Thomas PE, Wharram BL, Goyal M, Wiggins JE, Whiteside CI, Wiggins RC: Molecular cloning, expression, and characterization of podocalyxin-like protein 1 from rabbit as a transmembrane protein of glomerular podocytes and vascular endothelium. J Biol Chem 1995;270:29439-29446.

-2 Sassetti C, Tangemann K, Singer MS, Kershaw DB, Rosen SD: Identification of podocalyxin-like protein as a high endothelial venule ligand for L-selectin: parallels to CD34. J Exp Med 1998;187:1965-1975.

-3 Sassetti C, Van Zante A, Rosen SD: Identification of endoglycan, a member of the CD34/ podocalyxin family of sialomucins. J Biol Chem 2000;275:9001-9010.

-4 Kerjaschki D, Sharkey DJ, Farquhar MG: Identification and characterization of podocalyxin - the major sialoprotein of the renal glomerular epithelial cell. J Cell Biol 1984;98: 1591-1596.

\footnotetext{
5 Doyonnas R, Nielsen JS, Chelliah S, Drew E, Hara T, Miyajima A, McNagny KM: Podocalyxin is a CD34-related marker of murine hematopoietic stem cells and embryonic erythroid cells. Blood 2005;105:4170-4178.

6 Cai J, Chen J, Liu Y, Miura T, Luo Y, Loring JF, Freed WJ, Rao MS, Zeng X: Assessing self-renewal and differentiation in human embryonic stem cell lines. Stem Cells 2006; 24:516-530.

7 Heukamp LC, Fischer HP, Schirmacher P, Chen X, Breuhahn K, Nicolay C, Buttner R, Gutgemann I: Podocalyxin-like protein 1 expression in primary hepatic tumours and tumour-like lesions. Histopathology 2006;49: 242-247.

8 Casey G, Neville PJ, Liu X, Plummer SJ, Cicek MS, Krumroy LM, Curran AP, McGreevy MR, Catalona WJ, Klein EA, Witte JS: Podocalyxin variants and risk of prostate cancer and tumor aggressiveness. Hum Mol Genet 2006;15:735-741.
}

9 Kelley TW, Huntsman D, McNagny KM, Roskelley CD, Hsi ED: Podocalyxin: a marker of blasts in acute leukemia. Am J Clin Pathol 2005;124:134-142.

-10 Yasuoka H, Tsujimoto M, Hirokawa M, Tori M, Nakahara M, Miyauchi A, Kodama R, Sanke T, Nakamura Y: Podocalyxin expression in undifferentiated thyroid carcinomas. J Clin Pathol 2008;61:1228-1229.

- 11 Somasiri A, Nielsen JS, Makretsov N, McCoy ML, Prentice L, Gilks CB, Chia SK, Gelmon KA, Kershaw DB, Huntsman DG, McNagny $\mathrm{KM}$, Roskelley CD: Overexpression of the anti-adhesin podocalyxin is an independent predictor of breast cancer progression. Cancer Res 2004;64:5068-5073.

12 Hayatsu N, Kaneko MK, Mishima K, Nishikawa R, Matsutani M, Price JE, Kato Y: Podocalyxin expression in malignant astrocytic tumors. Biochem Biophys Res Commun 2008;374:394-398. 
-13 Schopperle WM, Kershaw DB, DeWolf WC: Human embryonal carcinoma tumor antigen, Gp200/GCTM-2, is podocalyxin. Biochem Biophys Res Commun 2003;300:285290.

- 14 Stanhope-Baker P, Kessler PM, Li W, Agarwal ML, Williams BR: The Wilms tumor suppressor-1 target gene podocalyxin is transcriptionally repressed by p53. J Biol Chem 2004;279:33575-33585.

15 Sundfeldt K: Cell-cell adhesion in the normal ovary and ovarian tumors of epithelial origin: an exception to the rule. Mol Cell Endocrinol 2003;202:89-96.

16 Gardner MJ, Jones LM, Catterall JB, Turner GA: Expression of cell adhesion molecules on ovarian tumour cell lines and mesothelial cells, in relation to ovarian cancer metastasis. Cancer Lett 1995;91:229-234.
7 Kershaw DB, Wiggins JE, Wharram BL, Wiggins RC: Assignment of the human podocalyxin-like protein (PODXL) gene to 7q32-q33. Genomics 1997;45:239-240.

-18 Nielsen JS, McNagny KM: The role of podocalyxin in health and disease. J Am Soc Nephrol 2009;20:1669-1676.

19 Takeda T, Go WY, Orlando RA, Farquhar MG: Expression of podocalyxin inhibits cellcell adhesion and modifies junctional properties in Madin-Darby canine kidney cells. Mol Biol Cell 2000;11:3219-3232.

20 Pan Y, Jiao J, Zhou C, Cheng Q, Hu Y, Chen $\mathrm{H}$ : Nanog is highly expressed in ovarian serous cystadenocarcinoma and correlated with clinical stage and pathological grade. Pathobiology 2010;77:283-288.

21 Thomas SN, Tong Z, Stebe KJ, Konstantopoulos K: Identification, characterization and utilization of tumor cell selectin ligands in the design of colon cancer diagnostics. Biorheology 2009;46:207-225.
22 Thomas SN, Schnaar RL, Konstantopoulos $\mathrm{K}$ : Podocalyxin-like protein is an E-/L-selectin ligand on colon carcinoma cells: comparative biochemical properties of selectin ligands in host and tumor cells. Am J Physiol Cell Physiol 2009;296:C505-C513.

$\checkmark 23$ Choo AB, Tan HL, Ang SN, Fong WJ, Chin A, Lo J, Zheng L, Hentze H, Philp RJ, Oh SK, Yap M: Selection against undifferentiated human embryonic stem cells by a cytotoxic antibody recognizing podocalyxin-like protein-1. Stem Cells 2008;26:1454-1463.

24 Ney JT, Zhou H, Sipos B, Buttner R, Chen X, Kloppel G, Gutgemann I: Podocalyxin-like protein 1 expression is useful to differentiate pancreatic ductal adenocarcinomas from adenocarcinomas of the biliary and gastrointestinal tracts. Hum Pathol 2007;38:359364 . 